Review Article

\title{
Attracting International Students: Experiences of Asian Countries and the Case of University of Social Sciences and Humanities, Vietnam National University-Ho Chi Minh
}

\author{
Mai Thi Kim Khanh*, Chau Huy Ngoc \\ University of Social Sciences and Humanities, Vietnam National University-Ho Chi Minh, \\ 10-12 Dinh Tien Hoang, District 1, Ho Chi Minh City, Vietnam
}

Received 21 February 2021

Revised 02 August 2021; Accepted 21 August 2021

\begin{abstract}
In recent years, internationalization of higher education has become a guiding agenda and a policy both at the Party and Government's levels, and of which international student recruitment is seen as an important measure which could improve higher education institutions' international orientation, contribute to reputation and international university rankings. Hence learning from countries which have successfully internationalized their higher educations in order to draw lessons for universities in Vietnam to utilize their existing advantages and remedy shortcomings in internationalization is a necessity. This article serves as an overview of experiences of Asian countries based on studies conducted in China, Taiwan, and Korea, which suggest that languages and distinctive cultural elements could be important factors attracting international students to these Asian destinations. University of Social Sciences and Humanites will then be presented as a Vietnamese higher education institution that could become a destination of foreign students using its distinctive strengths, namely Vietnamese language and Vietnamese Studies programs and cultural exchange activities.
\end{abstract}

Keywords: International students, attract international students, Asian experiences, University of Social Sciences and Humanities, Vietnam National University-Ho Chi Minh (VNU-HCM).

\footnotetext{
* Corresponding author.

E-mail address: kimkhanhmai@ hcmussh.edu.vn

https://doi.org/10.25073/2588-1159/vnuer.4504
} 


\title{
Thu hút sinh viên quốc tế: kinh nghiệm châu Á và trường hợp Trường Đại học Khoa học Xã hội và Nhân văn, Đại học Quốc gia Thành phố Hồ Chí Minh
}

\author{
Mai Thị Kim Khánh*, Châu Huy Ngọc \\ Trường Đại học Khoa học Xã hội và Nhân văn, Đại học Quốc gia Thành phố Hồ Chí Minh, \\ 10-12 Đinh Tiên Hoàng, Quận 1, Thành phố Hồ Chí Minh, Việt Nam \\ Nhận ngày 21 tháng 02 năm 2021 \\ Chỉnh sửa ngày 02 tháng 8 năm 2021; Chấp nhận đăng ngày 21 tháng 8 năm 2021
}

\begin{abstract}
Tóm tắt: Trong những năm gần đây, quốc tế hóa giáo dục đại học đã trở thành chủ trương của Đảng và chính sách của nhà nước, trong đó thu hút sinh viên quốc tế được xem là một trong những yếu tố quan trọng nâng cao mức độ quốc tế hóa của cơ sở giáo dục đại học, góp phần xây dựng danh tiếng của nhà trường và có ảnh hưởng đến thứ hạng của cơ sở giáo dục đại học trên các bảng xếp hạng đại học quốc tế. Việc tham khảo kinh nghiệm của các quốc gia đã có những thành tựu quốc tế hóa giáo dục để từ đó nhìn lại những điều kiện sẵn có nhằm phát huy các cơ hội của thế mạnh nội tại và cải tiến những mặt hạn chế là cần thiết. Do vậy, trong bài viết này chúng tôi sẽ giới thiệu các kinh nghiệm của các quốc gia và vùng lãnh thổ châu Á, trên cơ sở những nghiên cứu đã thực hiện ở Trung Quốc, Đài Loan và Hàn Quốc đã cho thấy ngôn ngữ và văn hóa đặc trưng là những yếu tố quan trọng thu hút sinh viên quốc tế đến châu Á. Bên cạnh đó, Trường Đại học Khoa học Xã hội và Nhân văn, Đại học Quốc gia Thành phố Hồ Chí Minh (ĐHQG-HCM) cũng được giới thiệu như một cơ sở giáo dục đại học tại Việt Nam thành công trong việc thu hút sinh viên quốc tế với việc vận dụng hiệu quả những thế mạnh của chương trình giảng dạy tiếng Việt, đào tạo Việt Nam học, và các hoạt động giao lưu văn hóa.
\end{abstract}

Từ khóa: Sinh viên quốc tế, thu hút sinh viên quốc tế, kinh nghiệm châu Á, Trường Đại học Khoa học Xã hội và Nhân văn, ĐHQG-HCM.

\section{1. Đặt vấn đề}

Trong những năm trở lại đây, tăng cường hội nhập quốc tể được khẳng định là một trong những nhiệm vụ và giải pháp trọng tâm trong đổi mới căn bản và toàn diện nền giáo dục nước ta. Quan điểm này được thể hiện xuyên suốt qua các chủ trương, chính sách của Đảng và Nhà nước, cụ thể là "Chiến lược phát triển giáo dục 2011-2020" được Thủ tướng Chính phủ ban hành ngày 13/6/2012 và Nghị quyết số 29-NQ/TW ngày 4/11/2013 về đổi mới căn bản, toàn diện Giáo dục và Đào tạo của Bộ Chính trị.

\footnotetext{
* Tác giả liên hệ.

Địa chỉ email: kimkhanhmai@ @cmussh.edu.vn

https://doi.org/10.25073/2588-1159/vnuer.4504
}

Theo đó, các giải pháp được đề ra bao gồm: đẩy mạnh gửi đi và đào tạo nhân lực ở các nước phát triển, khuyến khích các cơ sở giáo dục và đào tạo trong nước hợp tác với các cơ sở ở nước ngoài, đẩy mạnh các hoạt động giao lưu văn hóa và học thuật quốc tế, thu hút nguồn lực từ các nước trên thế giới đóng góp vào giáo dục Việt Nam [1,2]. Quyết định 69/QĐ-TTg được Thủ tướng Chính phủ ban hành ngày 15 tháng 01 năm 2019 về việc phê duyệt Đề án nâng cao chất lượng giáo dục đại học giai đoạn 2019-2025 đã đưa quốc tế hóa giáo dục đại học thành một nhiệm vụ nhằm thực hiện mục tiêu hội nhập quốc tế trong giáo dục đại học, và việc thu hút sinh viên quốc tế đến học tập là một trong các giải pháp quan trọng [3]. 
Việc thu hút hút sinh viên quốc tế có vai trò và ý nghĩa hết sức quan trọng góp phần xây dựng hình ảnh, thương hiệu và nâng cao năng lực cạnh tranh của các trường đại học ở tầm khu vực và toàn cầu. Sự hiện diện của sinh viên quốc tế mang lại sự đa dạng văn hóa, góp phần nâng cao chất lượng của cơ sở giáo dục đại học mà mình theo học. Có thể nói sư hiện diện của sinh viên quốc tế là một vấn đề không thể bỏ qua trong quá trình quốc tế hóa của một trường đại học, chính nhóm sinh viên này sẽ là nhân tố đóng góp vào danh tiếng nhà trường trên bình diện quốc gia cũng như quốc tế, tăng cường sự hiện diện của trường trên quy mô toàn cầu và góp phần tăng thứ hạng trên các bảng xếp hạng đại học quốc tế [4].

\section{Phương pháp nghiên cứu và khái niệm}

Trong nghiên cứu này, chúng tôi đã sử dụng phương pháp tổng hợp tài liệu từ nghiên cứu của các nhà khoa học đã được công bố trên các tạp chí uy tín trong lĩnh vực giáo dục đại học trên thế giới trong khoảng 10 năm trở lại đây và nguồn thông tin, số liệu báo cáo từ hai cơ sở sở giáo dục đại học ĐHQG-HCM và Trường Đại học Khoa học Xã hội và Nhân văn, ĐHQG-HCM. Kết hợp với kết quả khảo sát của đề tài cấp cơ sở "Trải nghiệm của sinh viên quốc tế về các hoạt động hoc tập tại Truờng Đại học Khoa họ Xã họi và Nhân văn, ĐHQG-HCM", được thực hiện trong năm 2020. Từ các tài liệu đã tổng hợp chúng tôi tiến hành phân tích, đánh giá và đưa ra những đề xuất liên quan đến chiến lược thu hút sinh viên quốc tế tại các cơ sở giáo dục đại học tại Việt Nam.

Nhóm tác giả cũng vận dụng mô hình lực đẩy - sức hút của Mazzarol và Soutar [5] như một khung lý thuyết quan trọng để lý giải dòng chảy sinh viên quốc tế và những trải nghiệm về sự hài lòng của sinh viên quốc tế tại các cơ sở giáo dục đại học tại quốc gia tiếp nhận. Chúng tôi sẽ phân tích trường hợp Trung Quốc, Đài Loan và Hàn Quốc để tìm hiểu những yếu tố đặc trưng thu hút sinh viên quốc tế của các trường đại học tại các quốc gia và vùng lãnh thổ này.

Trong bài viết chúng tôi sử dụng khái niệm sinh viên quốc tế để chỉ những người rời khỏi quê hương mình để đến một quốc gia khác vì mục đích học tập [6]. Sinh viên quốc tế được phân loại bao gồm sinh viên tham gia các khóa đào tạo chính quy và sinh viên tham gia các khóa đào tạo, trao đổi ngắn hạn.

\section{Mô hình "lực đẩy - sức hút" trong chuyển dịch sinh viên quốc tế, đánh giá sự hài lòng và các chiến lược thu hút sinh viên quốc tế ở châu Á}

\subsection{Cách tiếp cận mô hình "lực đẩy-sưc hút" và tầm quan trọng của sụ hài lòng của trải nghiệm học tập đối với hình ảnh và danh tiếng của nhà trưòng}

Mô hình lực đẩy-sức hút ban đầu được đưa ra nhằm hệ thống hóa những nhân tố ảnh hưởng đến di cư. Sau đó, những nhà nghiên cứu giáo dục đã áp dụng khung lý thuyết này để tìm hiểu những nhân tố ảnh hưởng đến việc lựa chọn quốc gia đến của sinh viên đi du học. Trong đó nhân tố "sức hút" chính là những kỳ vọng về nền giáo dục của quốc gia điểm đến và những yếu tố kinh tế xã hội hấp dẫn có liên quan đến việc tuyển sinh sinh viên quốc tế. Các yếu tố liên quan bao gồm: kiến thức và hiểu biết về quốc gia đến, những gợi ý của bạn bè và người thân, mối quan tâm về chi phí, những vấn đề liên quan đến môi trường học thuật, kết nối xã hội và gần gũi về địa lý cũng đóng vai trò quan trọng trong việc thu hút sinh viên quốc tế. Những nhân tố "lực đẩy" là sự không thoả mãn của người học về những cơ hội giáo dục tại quê nhà, điều đó đã tạo áp lực để họ ra đi và theo đuổi một nền giáo dục khác. Nguồn gốc của sự không thoả mãn này bao gồm những khó khăn trong việc vào được một trường đại học tại quê nhà, không tìm được chương trình đào tạo ưng ý trong nước, sự hấp dẫn của các chương trình giảng dạy ngoài nước, cũng như mong muốn hiểu biết nhiều hơn về phương Tây và dự định di cư [5].

Mô hình "lực đẩy-sức hút" của Mazzarol và Soutar [5] đã có đóng góp quan trọng trong việc xác định và phân loại những yếu tố tác động đến quyết định rời khỏi quốc gia mình sinh sống để lựa chọn học tập ở một quốc gia khác 
của các sinh viên quốc tế. Tuy nhiên, mô hình "lực đẩy-sức hút" này vẫn có những hạn chế khi áp dụng vào phân tích động lực của sinh viên quốc tế đến học tập ở những quốc gia và vùng lãnh thổ châu Á đang nổi lên trong thị trường giáo dục quốc tế như Hàn Quốc, Trung Quốc, Đài Loan và Việt Nam. Bởi vì những sinh viên quốc tế từ nhiều nơi trên thế giới đến học tập tại các quốc gia ở châu Á một mặt cũng chia sẻ những động lực tương tự như những người học từ các quốc gia châu Â đến học tập tại các quốc gia phát triển nói tiếng Anh, nhưng mặt khác họ lại có những đặc thù riêng đòi hỏi cần được nghiên cứu cụ thể hơn để góp phần làm sáng tỏ nguyên nhân lựa chọn cũng như những trải nghiệm của họ trong quá trình học tập. Những kết quả được tìm thấy trong các nghiên cứu của Lee [7] và Ahmad và Buchanan [8] là những ví dụ điển hình cho thấy dù khẳng định danh tiếng của trường đại học điểm đến có vai trò quan trọng, nhưng họ vẫn thấy sinh viên quốc tế đến học tập tại các quốc gia châu Á được thu hút bởi các yếu tố như học phí thấp, tương đồng văn hóa, khoảng cách địa lý hoặc mức độ cạnh tranh vào đại học không gay gắt như ở quê nhà.

Bên cạnh việc tìm hiểu các yếu tố tạo sự thu hút ban đầu tác động đến quyết định lựa chọn điểm đến du học thì việc thực hiện những đánh giá về mức độ hài lòng của sinh viên trong quá trình học tập cũng rất quan trọng. Bởi vì sự hài lòng chính là sự đánh giá tích cực của sinh viên về kết quả và trải nghiệm liên quan đến các hoạt động học tập [9], sự hài lòng này sẽ tác động trực tiếp đến kết quả học tập, hứng thú học tập cũng như sự kiên trì theo đuồi quá trình học tập của họ tại nơi đến [10]. Những đánh giá tích cực của sinh viên có mối quan hệ mật thiết với những mong đợi của họ đối với trải nghiệm học tập, nếu như sinh viên có những trải nghiệm thực tế tốt hơn những điều kỳ vọng sẽ mang lại cho họ sự hài lòng [11]. Vì thế cần phải hiểu rõ những mong muốn của sinh viên quốc tế và đánh giá mức độ tích cực của những trải nghiệm học tập để không những có thể thu hút mà còn duy trì số lượng sinh viên quốc tế theo hướng bền vững vì chính sự hài lòng này là cơ sở để thu hút thêm nhiều sinh viên quốc tế đến học tập.

\subsection{Các quốc gia châu Á và chiến luợc thu hút sinh viên quốc tế}

\subsubsection{Trung Quốc}

Trong hai thập kỷ trở lại đây, chính phủ Trung Quốc đã có những chính sách thu hút sinh viên quốc tế đến học tập tại các trường đại học trong nước [4]. Cùng với việc các trường đại học Trung Quốc dần xuất hiện nhiều hơn trên các bảng xếp hạng quốc tế, như đã nói ở trên, Bộ Giáo dục Trung Quốc đã khởi động chương trình "Study in China" với mục tiêu cụ thể là thu hút khoảng 500.000 sinh viên quốc tế vào năm 2020, trong đó có 150.000 sinh viên chính quy [4]. Kết quả là số lượng sinh viên quốc tế đến học tập ở Trung Quốc đã gia tăng đáng kể trong hai thập kỷ trở lại đây, đạt gần nửa triệu du học sinh đến từ hơn 200 quốc gia và vùng lãnh thổ trong năm 2018 [12].

Không chỉ tăng nhanh về số lượng, mà địa bàn phân bố sinh viên quốc tế tại các địa phương có trường đại học cũng đa dạng hóa đáng kể. Nếu trước đây các đối tượng người học nước ngoài chỉ tập trung vào hai thành phố lớn là Thượng Hải và Bắc Kinh thì hiện nay 31/33 tỉnh, thành, khu tự trị, khu hành chính đặc biệt đều có trường đại học tiếp nhận sinh viền quốc tế. Mặc dù Bắc Kinh và Thượng Hải vẫn là hai địa phương đón nhận du học sinh nhiều nhất, nhưng các tỉnh, thành khác cũng mở rộng quy mô đón nhận sinh viên quốc tế của mình. Ở thời điểm 2016 , gần $70 \% \mathrm{du}$ học sinh đến Trung Quốc tập trung ở các địa phương ngoài Bắc Kinh và Thượng Hải [13], chỉ riêng ở tỉnh Tứ Xuyên, số lượng sinh viên quốc tế đã tăng từ 1,846 vào năm 2010 lên 10,796 năm 2016 [14].

Sự gia tăng nhanh chóng của sinh viên quốc tế cho thấy Trung Quốc đang trở thành một điểm đến hấp dẫn quan trọng ở châu Á. Ding [15] cho thây có đển $76 \%$ sinh viên được hỏi cho biết Trung Quốc là lựa chọn đầu tiên của họ khi cân nhắc điểm đến du học, kết quả này cho thấy đã có nhiều yếu tố sức hút ảnh hưởng đến quá trình này. Hầu hết các mẫu khảo sát trong nghiên cứu của Jiani [16] đều nhấn mạnh đến triển vọng phát triển kinh tế trong tương lai của Trung Quốc như là yếu tố hàng đầu thu hút sinh 
viên quốc tế, yếu tố này khi song hành với hiện trạng quan hệ ngoại giao tốt đẹp của Trung Quốc với quốc gia quê nhà của người học lại càng có vai trò quan trọng ở tầm vĩ mô thu hút họ đến học tập tại quốc gia này.

Ngoài ra, Trung Quốc với vị thế là cường quốc kinh tế trên thế giới đã khiến cho tiếng Trung có vai trò ngày càng quan trọng ở quy mô toàn cầu, đây chính là một trong những sức hút hàng đầu có ảnh hưởng đến quyết định của người học lựa chọn Trung Quốc như một điểm đến du học. Các nghiên cứu trước đây của Mazzarol và Soutar [5], Park [17] và Lee [7] đều cùng cho rằng viễn cảnh gia tăng cơ hội việc làm sau khi tốt nghiệp là yếu tố sức hút quan trọng đối với sinh viên quốc tế. Các kết quả khảo sát của Ding [15], Jiani [16] và Ahmad và Shah [18] đã củng cố thêm quan điểm này khi cho thấy người học xem việc thông thạo tiếng Trung sẽ giúp họ có được cơ hội việc làm tốt hơn sau tốt nghiệp.

Những yếu tố sức hút khác cũng có tác động đáng kể đến quyết định lựa chọn điểm đến của sinh viên quốc tế. Công trình của Ding [15] cho thấy danh tiếng học thuật của các trường đại học, những khóa học đáp ứng được nhu cầu, bằng cấp được công nhận và học bổng hỗ trợ học tập cũng là những yếu tố sức hút quan trọng đối với du học sinh. Hỗ trợ tài chính và chất lượng học thuật cũng được xem là các yếu tố quan trọng trong nghiên cứu của Jiani [16] và một số công trình khác như của Ahmad và Shah [18] và Gbollie và Gong [19].

Có thể thấy các yếu tố thu hút sinh viên quốc tế đến học tập tại Trung Quốc như danh tiếng học thuật của quốc gia điểm đến hay những hỗ trợ tài chính là các yếu tố đã được nhắc đến trong mô hình của Mazzarol và Soutar [5]. Đồng thời các công trình nghiên cứu Ding [15] và Jiani [16], Lu và cộng sự [14] cũng đã chỉ ra ngoài yếu tố đặc trưng riêng như cơ hội học tập tiếng Trung thì các khóa học gắn liền với trải nghiệm văn hóa Trung Quốc được xem là những yếu tố thu hút sinh viên quốc tế hàng đầu chọn quốc gia này.

Như vậy trường hợp Trung Quốc cho thấy sự gia tăng nhanh chóng của sinh viên quốc tế trong hai mươi năm trở lại đây là kết quả của nhiều giải pháp đã được chính phủ Trung Quốc phát triển, đặc biệt tập trung mũi nhọn vào các chương trình quốc tế giảng dạy bằng tiếng Anh bên cạnh việc tiếp tục đầu tư xây dựng các khóa học "đậm đà bản sắc Trung Hoa" vốn đã làm nên lợi thế cạnh tranh của Trung Quốc trên thị trường giáo dục quốc tế; bên cạnh đó là tăng cường các chương trình học bổng cho sinh viên quốc tế ở cấp quốc gia, địa phương và trường đại học; cũng như nâng cao năng lực quảng bá hình ảnh ở nhiều mức độ khác nhau; và xây dựng mạng lưới cựu sinh viên quốc tế [4]. Như vậy có thể thấy bên cạnh chiến lược tập trung xây dựng các chương trình tiên tiến giảng dạy bằng tiếng Anh để thu hút sinh viên quốc tế như các quốc gia có truyền thống tiếp nhận du học sinh trên thế giới, Trung Quốc đã tận dụng được sức hút riêng của mình để thu hút nhóm đối tượng người học này bằng các chương trình giảng dạy bằng ngôn ngữ tiểng Trung và những yếu tố trải nghiệm văn hóa đặc trưng đang ngày càng trở nên hấp dẫn hơn nhờ vị thế là một trong những cường quốc kinh tế trên thế giới

\subsection{2. Đài Loan}

Đài Loan cũng đang được xem là một điểm đến quan trợg của sinh viên quốc tế trong khu vực châu Á. Kể từ những năm 2000, chính quyền của vùng lãnh thổ này đã có những chính sách và chiến lược tích cực nhằm tăng cường số lượng sinh viên quốc tế theo học tại các trường đại học ở đây. Mục tiêu của các chính sách này hướng đến: i) Quốc tế hóa nền giáo dục đại học trong nước nhằm nâng cao danh tiếng và chất lượng; ii) Bù đắp lại số lượng sinh viên nội địa đang suy giảm do quá trình già hóa dân số; và iii) Góp phần nâng cao thứ hạng của các trường đại học Đài Loan trong các bảng xếp hạng đại học trên thế giới [20]. Số liệu trong 10 năm trở lại đây cho thấy số lượng sinh viên quốc tế chọn Đài Loan làm điểm đến học tập đã gia tăng đáng kể từ hơn 39.000 năm 2009 lên đến gần 127.000 người vào năm 2018 [21], tổng số sinh viên quốc tế tại đây đã tương đương $10 \%$ tổng số sinh viên đại học [22].

Khảo sát của Roberts và cộng sự [23] cho thấy hai nhân tố có tác động lớn nhất đến việc sinh viên quốc tế quyết định chọn đến Đài Loan học tập, thứ nhất đó là cơ hội học bổng, với 
mong muốn thúc đẩy quá trình quốc tế hóa giáo dục trước tiên thông qua tăng cường số lượng sinh viên quốc tế, chính phủ Đài Loan đã có nhiều chương trình cấp học bổng cho các đối tượng người học ngoài nước muốn đến nơi này để học tập. Việc phê duyệt học bổng được thực hiện bởi các cơ quan đại diện ngoại giao của Đài Loan. Có đến $91 \%$ người tham gia nghiên cứu nhận được học bổng từ các chương trình học bổng của chính phủ Đài Loan. Và họ đánh giá đây là yếu tố quan trọng nhất ảnh hưởng đến quyết định chọn Đài Loan là điểm đến học tập. Điều thứ hai khiến Đài Loan trở thành một điểm đến hấp dẫn đó là chương trình đào tạo tiếng Trung. Ngoài Trung Quốc thì Đài Loan là nơi duy nhất trên thế giới sử dụng tiếng Trung làm ngôn ngữ chính thức. Cùng với sự trỗi dậy mạnh mẽ về kinh tế và tầm ảnh hưởng quốc tế của Trung Quốc, ngôn ngữ này đã thu hút được sự quan tâm và đang đóng vai trò quan trọng toàn cầu, và Đài Loan là một lựa chọn lý tưởng để theo học các chương trình tiếng Trung phục vụ mục tiêu nâng cao kỹ năng ngôn ngữ cho triển vọng công việc tương lai. Nghiên cứu của Wang và Chang [24] cũng cho thấy ngôn ngữ và văn hóa cổ truyền Trung Quốc, vốn đã được chính quyền Đài Loan bảo tồn xem như di sản, là yếu tố quan trọng nhất để thu hút sinh viên nước ngoài đến Đài Loan, với giá trị trung bình $5.70 / 6$ vượt xa yếu tố xếp thứ hai là danh tiếng học thuật 3.35/6.

Có thể nói Đài Loan đã trở thành một điểm đến hấp dẫn đối với sinh viên quốc tế nhờ vào hai yếu tố sức hút quan trọng nhất đó là cơ hội học bổng và sự hấp dẫn của văn hóa và ngôn ngữ [23, 24].

Đối với yếu tố thu hút của cơ sở đào tạo, Roberts và cộng sự [23], đã chỉ ra các lý do hàng đầu thu hút sinh viên quốc tế chọn điểm đến học tập bao gồm: gợi ý của bạn bè, chất lượng của chương trình đào tạo tiếng Trung và công tác tư vấn, hỗ trợ của cơ quan đại diện ngoại giao Đài Loan ở các quốc gia gửi sinh viên đến. Các yếu tố còn lại bao gồm: môi trường học tập, thông tin website, các chương trình đào tạo bằng tiếng Anh và các nguyên nhân khác chỉ chiếm vai trò không đáng kể.

\subsubsection{Hàn Quốc}

Kể từ năm 2004, chính phủ Hàn Quốc đã có những chính sách thu hút sinh viên quốc tế, cụ thể thông qua chương trình "Study in Korea" với mục tiêu thu hút 200.000 sinh viên quốc tế vào năm 2023 nhằm góp phần bù đắp vào số lượng sinh viên trong nước đang ngày càng giảm do tỷ lệ sinh thấp, tăng nguồn thu cho các cơ sở giáo dục đại học Hàn Quốc cũng như gia tăng liên kết với các quốc gia mà các doanh nghiệp Hàn Quốc hướng đến [25]. Số lượng sinh viên quốc tế đến Hàn Quốc gia tăng liên tục trong những năm trước đại dịch Covid-19 từ 91.332 năm 2015 lên 160.165 năm 2019 [26]. Ngay cả sau khi Covid-19 bùng phát, số lượng sinh viên quốc tế ở Hàn Quốc cũng vẫn duy trì được ở mức 153.695, tính đến thời điểm tháng 4 năm 2020 [27].

Đối với các yếu tố thu hút sinh viên quốc tế đến Hàn Quốc, nghiên cứu của Jon và cộng sự [28] cho thấy hai yếu tố quan trọng nhất để sinh viên quốc tế lựa chọn Hàn Quốc là điểm đến bao gồm "học và thực hành tiếng Hàn" và "trải nghiệm văn hóa Hàn Quốc", theo sau là "cơ hội học bổng", "cơ hội việc làm tốt hơn bên ngoài quê nhà với kinh nghiệm du học", "cơ hội việc làm tại quê nhà với kinh nghiệm học tập ở nước ngoài”. Khi xem xét sâu hơn về khu vực địa lý thì sinh viên quốc tế đến từ các khu vực khác nhau cũng thể hiện những kết quả khác nhau, so sánh với sinh viên đến từ Bắc Mỹ và Châu Âu, sinh viên từ các quốc gia lân cận trong khu vực Đông Á cho biết lý do chọn Hàn Quốc là điểm đến học tập vì vị trí địa lý gần gũi, visa thuận lợi, quy trình tuyển sinh dễ tiếp cận và mức độ an toàn xã hội. Về loại hình đào tạo, sinh viên quốc tế đến Hàn Quốc theo học các chương trình ngắn hạn vì hứng thú trong thực hành ngôn ngữ, trải nghiệm văn hóa hoặc nghiên cứu về Hàn Quốc. Trong khi các sinh viên theo học các chương trình chính quy lại lựa chọn Hàn Quốc vì các lý do như cơ hội học bổng, triển vọng việc làm và lời khuyên của thầy cô [28]. Các yếu tố này cũng được chỉ ra trong nghiên cứu của Alemu và Cordier [9] khi cho rằng sinh viên quốc tế đến Hàn Quốc là nhằm khám phá văn hóa và có những trải nghiệm mới, vì danh 
tiếng của chương trình đào tạo, văn hóa Hàn Quốc và cơ hội học bổng.

Nhìn chung sinh viên châu Á ưu tiên các khía cạnh thực tế như visa, gần nhà, chi phí sinh hoạt và an toàn hơn so với các sinh viên phương Tây. Sinh viên chính quy thể hiện mức độ quan tâm thấp hơn đối với văn hóa và ngôn ngữ Hàn Quốc so với các sinh viên quốc tế tham gia các khóa học ngắn hạn. Sinh viên quốc tế ở Hàn Quốc thích học tiếng Hàn hơn là học một ngôn ngữ khác ngoài tiếng Anh [28].

Như vậy các trường đại học ở Hàn Quốc xem xét những mối quan tâm và động lực khác nhau của các nhóm đối tượng khác nhau để đưa ra những chiến lược tuyển sinh phù hợp. Ví dụ như các trường mong muốn thu hút sinh viên quốc tế từ Bắc Mỹ hay châu Âu và sinh viên trao đổi ngắn hạn có thể thực hiện các chương trình quảng bá nhắm vào trải nghiệm văn hóa và du lịch Hàn quốc. Đối với sinh viên châu Á, đặc biệt là sinh viên Trung Quốc và những người học hệ chính quy, các trường thu hút bằng các thông tin về cơ hội học bổng và chi phí sinh hoạt như việc làm bán thời gian, các cơ hội thực tập.

Về những thành tựu đã đạt được của các cơ sở giáo dục đại học tại Châu Á cho thấy yếu tố thu hút tuyển sinh sinh viên quốc tế nổi bật bao gồm ngôn ngữ và văn hóa, thay vì chú trọng tuyệt đối vào việc sử dụng tiếng Anh trong giảng dạy. Đây là một thị trường ngách (niche market) trong thu hút sinh viên quốc tế mà các quốc gia Châu Á đã xác định là điểm mạnh và đang đẩy mạnh nhằm tạo sức hút, tăng cường tỷ lệ sinh viên nước ngoài song song với việc xây dựng và hoàn thiện các chương trình giảng dạy bằng tiếng Anh.

Như vậy có thể thấy rằng các quốc gia châu Á một mặt vẫn đóng góp vào dòng chuyển dịch sinh viên quốc tế trong vai trò là các quốc gia gửi đi (sending nations), mặt khác cũng đang vươn lên trở thành các quốc gia điểm đến (receiving nations) đón nhận ngày càng nhiều người học đến từ bên ngoài biên giới lãnh thổ của mình. Việc tìm hiểu những kinh nghiệm thu hút sinh viên quốc tế đến theo học tại các quốc gia và vùng lãnh thổ này sẽ cung cấp những cơ sở để từ đó các cơ sở giáo dục đại học ở nước ta có thể xây dựng định hướng và chiến lược phù hợp.

\section{Tiềm năng thu hút sinh viên quốc tế tại Trường Đại học Khoa học Xã hội và Nhân văn, Đại học Quốc gia Thành phố Hồ Chí Minh}

\subsection{Sinh viên quốc tế tại nhà trường}

Nghiên cứu các trường đại học tại Trung Quốc, Đài Loan và Hàn Quốc trong vấn đề này cho thấy các chương trình đào tạo ngôn ngữ, các yếu tố văn hóa và triển vọng kinh tế là các yếu tố thị trường ngách mà các trường đại học ở các quốc gia châu Á nói chung trong đó có Việt Nam có thể xem xét và tận dụng cơ hội trong chiến lược phát triển số lượng sinh viên quốc tế của mình. Có thể xem xét trường hợp Trường Đại học Khoa học Xã hội và Nhân văn, một trường thành viên của ĐHQG-HCM là một ví dụ cho việc đã vận dụng được thế mạnh của chương trình ngôn ngữ tiếng Việt, Việt Nam học và các chương trình giao lưu văn hóa để thu hút sinh viên quốc tế đến học tập.

ĐHQG-HCM trong vai trò là một trong hai đại học quốc gia của cả nước luôn xem chủ động hội nhập quốc tế và nâng cao chất lượng đào tạo hướng đến chuẩn quốc tế là hai trong các mũi chiến lược trọng tâm. Cụ thể, trong 5 năm từ 2015-2019, công tác tuyển sinh người nước ngoài và tăng cường giao lưu hợp tác quốc tế luôn được xem là những hoạt động quan trọng trong chiến lược đào tạo và hợp tác quốc tế của $\mathrm{OHQG-HCM}$ với định hướng vươn tầm khu vực châu Á. Chỉ tính riêng năm 2019, ĐHQG-HCM đã đón hơn 600 đoàn khách quốc tế đến thăm và thảo luận các cơ hội hợp tác trao đổi giảng viên và sinh viên, hơn 640 chuyên gia nước ngoài đến học tập, nghiên cứu và giảng dạy. Về số lượng sinh viên quốc tế, chỉ riêng năm 2019, các trường thuộc ĐHQG-HCM đã đón hơn 3,000 sinh viên nước ngoài đến tham gia các hoạt động giao lưu và học tập, trong đó ngắn hạn chiếm $74 \%$, chính quy và sau đại học chiếm $26 \%$ [29].

Với vai trò là một trường thành viên, Trường Đại học Khoa học Xã hội và Nhân văn, ĐHQG-HCM có thể xem là một cơ sở giáo dục đại học có nhiều đóng góp tiềm năng và triển 
vọng trong việc đào tạo người học đến từ nước ngoài thông qua chương trình đào tạo cử nhân Việt Nam học chính quy, các khóa học tiếng Việt ngắn hạn, cũng như các lớp trao đổi ngắn hạn về văn hóa, lịch sử Việt Nam. Theo số liệu từ Phòng Đối ngoại và Quản lý khoa học của Nhà trường, trong giai đoạn 5 năm từ 2015-2020, tổng số sinh viên chính quy là người nước ngoài theo học tại trường tăng hơn 60\% từ 206 năm 2015 lên 341 trong năm 2020, số học viên cao học người nước ngoài luôn dao động quanh mức 30 người, và số lượng người nước ngoài theo học các khóa tiếng Việt ngắn hạn luôn xấp xỉ ở mức 1.000 người [30], tỷ lệ sinh viên nước ngoài theo học các chương trình chính quy tại Trường Đại học Khoa học Xã hội và Nhân văn, ĐHQG-HCM là $3,2 \%$ (tỷ lệ này chưa bao gồm số liệu về sinh viên trao đổi ngắn hạn tại trường), cao hơn gần gấp 3 lần so với mức tổng của cả nước (tỷ lệ sinh viên nước ngoài tại Việt Nam là $1,2 \%$ ). Như vậy có thể thấy Trường Đại học Khoa học Xã hội và Nhân văn, ĐHQG-HCM đã phát huy được những ưu thế nhất định trong khả năng thu hút sinh viên quốc tế đến học tập các chương trình đào tạo Việt Nam học chính quy cũng như tiếng Việt ngắn hạn - trong vai trò là một cơ sở đào tạo Việt Nam học uy tín và lớn nhất khu vực phía Nam.

\subsection{Súc hút của chuoong trình đào tạo chính quy tại Nhà truoòng}

Trong khuôn khổ đề tài nghiên cứu khoa học cấp cơ sở "Trải nghiệm của sinh viên quốc tế về các hoạt động học tập tại Trường Đại học Khoa họ Xã hội và Nhân văn, ĐHQG-HCM", được thực hiện trong năm 2020, nhóm tác giả đã thực hiện khảo sát bảng hỏi 94 sinh viên và phỏng vấn bán cấu trúc 06 sinh viên, tất cả đều là sinh viên quốc tế đang theo học chương trình đào tạo Cử nhân Việt Nam học tại Trường Đại học Khoa học Xã hội và Nhân văn, ĐHQG-HCM. Kết quả khảo sát sinh viên quốc tế cho biết quyết định đến Việt Nam học tập do bị thu hút bởi: i) Triển vọng sức mạnh kinh tế của Việt Nam; ii) Muốn học tiếng Việt ngay tại Việt Nam; iii) Do yêu cầu phát triển công việc của bản thân và gia đình tại Việt Nam. Về lựa chọn cơ sở đào tạo, Chương trình đào tạo Cử nhân
Việt Nam học từ lâu đã trở thành "thương hiệu" để tuyển sinh sinh viên quốc tế của Trường Đại học Khoa học Xã hội và Nhân văn, ĐHQG-HCM, đồng thời Nhà trường đang là lựa chọn số một, nếu không muốn nói là duy nhất được các doanh nghiệp nước ngoài ở khu vực phía Nam, đặc biệt là Hàn Quốc ưu tiên tuyển dụng nhân sự có bằng cấp từ trường. Các sinh viên quốc tế tham gia khảo sát đều đánh giá danh tiếng của nhà trường chính là yếu tố sức hút hàng đầu để họ lựa chọn theo học. Ngoài ra, sau khi tốt nghiệp với bằng Cử nhân Việt Nam học từ Nhà trường, họ cũng có thể tìm được việc làm ở các doanh nghiệp nước ngoài tại Việt Nam hoặc tại quê hương sau khi về nước. Hình ảnh nhà trường, cơ hội việc làm và bằng cấp được công nhận là các yếu tố thu hút sinh viên quốc tế đến một quốc gia cụ thể để du học [5]. Nghiên cứu của chúng tôi đã cho thấy cơ sở giáo dục đại học tại Việt Nam, cụ thể là Trường Đại học Khoa học Xã hội và Nhân văn, ĐHQG-HCM đã vận dụng được các yếu tố này để thu hút sinh viên quốc tế.

Các sinh viên quốc tế này cũng là những hạt nhân quảng bá hình ảnh nhà trường cũng như góp phần thu hút thêm những sinh viên quốc tế khác cùng quốc tịch. Họ cho biết nếu có người thân hay bạn bè mong muốn ra nước ngoài học tập thì sẽ gợi ý đến Trường Đại học Khoa học Xã hội và Nhân văn, ĐHQG-HCM để theo học chương trình Việt Nam học.

\subsection{Các chuoong trình ngắn hạn}

Bên cạnh chương trình đào tạo Cử nhân Việt Nam học và Thạc sĩ Việt Nam học luôn duy trì số lượng sinh viên người nước ngoài ổn định qua các năm trước đại dịch Covid-19, Nhà trường còn tổ chức đều đặn các chương trình ngắn hạn với các đối tác nước ngoài. Các chương trình này có thời lượng tùy thuộc vào yêu cầu của đối tác dao động từ 2 đến 4 tuần. Riêng trong năm 2019, Khoa Việt Nam học đã đón 27 đoàn sinh viên ngắn hạn từ các trường đại học và tổ chức đối tác từ Mỹ, Úc và các quốc gia châu Á tham gia các khóa đào tạo tiếng Việt ngắn hạn, các hoạt động tìm hiểu khám phá đất nước-con người Việt Nam hoặc các nội dung chuyên sâu đi vào tìm hiểu lịch sử, văn hóa, kinh tế-xã hội. 
Trung tâm Đào tạo Quốc tế (CIE) thuộc Trường Đại học Khoa học Xã hội và Nhân văn, ĐHQG-HCM là một đơn vị thu hút đều đặn số lượng sinh viên quốc tế giao lưu ngắn hạn thông qua chương trình "Vietnam Study Program". Nội dung của chương trình bao gồm các buổi seminar kết hợp với tham quan thực tế và các hoạt động trao đổi văn hóa giữa sinh viên quốc tế và sinh viên Trường Đại học Khoa học Xã hội và Nhân văn, ĐHQG-HCM nhằm tăng cường hiểu biết về đất nước, văn hóa, tôn giáo và phong tục tập quán Việt Nam. Sinh viên sẽ được tham dự các khóa học theo chủ đề lịch sử, văn hóa, xã hội, quan hệ quốc tế và kinh tế Việt Nam do các giảng viên nhiều kinh nghiệm của Nhà trường phụ trách. Các sinh viên quốc tế có cơ hội tham gia chương trình còn trải nghiệm các hoạt động thực tế như tham quan doanh nghiệp, các cơ sở từ thiện, tìm hiểu về Đồng bằng sông Cửu Long, các di tích lịch sử địa phương, thăm quan bảo tàng,... Họ còn có các hoạt động trao đổi văn hóa với sinh viên Trường Đại học Khoa học Xã hội và Nhân văn, ĐHQG-HCM nhằm tăng cường hiểu biết lẫn nhau thông qua các hoạt động tập học tập nhóm, cùng chơi các trò chơi dân gian xuyên suốt chương trình.

\section{Kết luận và đề xuất}

\subsection{Kết luận}

Thu hút sinh viên quốc tế là một trong những thành tố quan trọng góp phần vào quá trình quốc tế hóa giáo dục đại học ở các quốc gia trên thế giới, để thực hiện hiệu quả công tác này, vấn đề quan trọng là phải xác định được những yếu tố sức hút tác động đến quá trình lựa chọn điểm đến học tập của sinh viên quốc tế, từ đó sẽ xác định những thế mạnh đặc trưng để có chiến lược cụ thể để nâng cao số lượng cũng như cải tiến chất lượng các chương trình đào tạo.

Sinh viên quốc tế đến các quốc gia phương Tây như Mỹ, Anh, Úc, và Đức vì sự hấp dẫn của chương trình đào tạo và danh tiếng học thuật lâu đời, thì các quốc gia châu Á cũng đang gia tăng số lượng người học đến từ ngoài nước bằng thế mạnh riêng của mình, đồng thời cũng tập trung xây dựng các chiến lược nâng cao chất lượng và danh tiếng học thuật. Thực tiễn từ một số quốc gia và vùng lãnh thổ ở châu Á bao gồm Trung Quốc, Đài Loan và Hàn Quốc cho thấy sau gần hai thập kỷ triển khai các chiến lược thu hút sinh viên quốc tế ở tầm quốc gia, địa phương và cơ sở đào tạo, số lượng người học từ ngoài nước đến học tập ở các chương trình đào tạo chính quy lẫn ngắn hạn đã gia tăng đáng kể và góp phần xây dựng các điểm đển này trở thành những cái tên mới nổi trong thị trường giáo dục quốc tế.

Có nhiều yếu tố làm nên sự hấp dẫn của các điểm đến châu Á đối với sinh viên quốc tế. Các nghiên cứu từ Trung Quốc, Đài Loan và Hàn Quốc đã nhấn mạnh đến học tập ngôn ngữ, giao lưu văn hóa, triển vọng phát triển kinh tế và cơ hội học bổng như là những yếu tố thu hút sinh viên quốc tế đặc trưng của các quốc gia và vùng lãnh thổ này. Từ đó nhìn về nước ta có thể thấy với một nền văn hóa đậm đà bản sắc dân tộc, bề dày truyền thống lịch sử, nền kinh tế hội nhập quốc tế và đang phát triển, Việt Nam cũng có những lợi thế tương tự các quốc gia châu Â để thu hút sinh viên quốc tế. Khảo sát sinh viên quốc tế đến học tập tại Trường Đại học Khoa học Xã hội và Nhân văn, ĐHQG-HCM đã cho thấy chương trình đào tạo chính quy Việt Nam học, và các chương trình ngắn hạn cũng như triển vọng phát triển kinh tế của Việt Nam là những yếu tố thu hút sinh viên quốc tế đến học tập tại Nhà trường với số lượng gần 1.000 lượt sinh viên mỗi năm chưa tính số lượng người nước ngoài học vãng lai chương trình tiếng Việt.

\section{2. Đề xuất}

Trong bối cảnh tăng cường tuyển sinh người học đến từ ngoài nước là một trong những giải pháp quan trọng phục vụ nhiệm vụ quốc tế hóa giáo dục đại học ở Việt Nam, nhận định này đã mang lại những hàm nghĩa và gợi ý cho các cơ sở giáo dục đại học ở nước ta. Các trường đại học tại Việt Nam với thế mạnh hiện có trong đào tạo ngôn ngữ, kết hợp với kinh tế đất nước được dự báo nhiều triển vọng phát triển trong tương lai, các chương trình tiếng Việt có thể được xem là một thế mạnh tạo nên thị trường ngách trong thu hút sinh viên quốc tế 
đến học tập tại Việt Nam. Đặc biệt, biến cố đại dịch Covid-19 đã khiến cho các tập đoàn đa quốc gia đang chuyển các hoạt động sản xuất ra khỏi Trung Quốc [31], Việt Nam đang đứng trước một cơ hội đón nhận làn sóng đầu tư tiếp theo mà đi cùng với nó là hàng loạt các cơ hội tăng cường hội nhập quốc tế ngày càng sâu rộng trên mọi lĩnh vực trong đó có giáo dục đại học. Vì thế các trường đại học cần có những chiến lược hợp lý vận dụng thế mạnh hiện có trong đào tạo tiếng Việt và văn hóa Việt Nam cho người nước ngoài để sẵn sàng đáp ứng các yêu cầu của người học nước ngoài có nhu cầu nâng cao năng lực ngôn ngữ cũng như hiểu biết hơn về đất nước.

Nhận thức được lợi thế cạnh tranh của ngôn ngữ và văn hóa đặc trưng trên thị trường giáo dục quốc tế, các trường đại học Việt Nam cần có chiến lược với mục tiêu cụ thể để xác định các yếu tố thu hút sinh viên quốc tế lựa chọn Việt Nam là điểm đến học tập, lấy đào tạo tiếng Việt, văn hóa Việt Nam và Việt Nam học làm đòn bẩy để đẩy mạnh tuyển sinh người học đến từ các quốc gia trong khu vực và thế giới. Ngoài ra, các trường đại học cần kết hợp với các cơ quan ngoại giao và ngành du lịch để mở rộng các kênh thông tin để có thể từ đó tăng thêm độ phủ bên cạnh các kênh đối tác quốc tế truyền thống. Để có thể làm được điều này, chúng tôi đề nghị cần có các nghiên cứu thực chứng đối với đối tượng sinh viên quốc tế đang học tập tại Việt Nam để có những hiểu biết sâu hơn về những mục tiêu, nguyện vọng, trải nghiệm của nhóm đối tượng này từ đó làm cơ sở để xây dựng chiến lược, kế hoạch hợp lý, từng bước nâng cao số lượng sinh viên nước ngoài theo học ở các chương trình đại học trong nước, ghi dấu Việt Nam lên bản đồ dòng chảy sinh viên toàn cầu như là một điểm đến thay vì chỉ là điểm gửi thuần túy, từ đó làm cơ sở để đón nhận thêm sinh viên quốc tế đến học tập một khi các trường đại học nước ta dần có vị thế cao hơn trên nền giáo dục đại học toàn cầu.

\section{Tài liệu tham khảo}

[1] Government of Vietnam, Education Development Strategy 2011-2020 (Promulgated Together with the Prime Minister's Decision No. 711/QĐ-TTg of June $13^{\text {th }}, 2012$ ),

http://vanban.chinhphu.vn/portal/page/portal/chin hphu/hethongvanban?class_id $=2 \&$ mode $=$ detail \&d ocument_id=160806/, 2012 (accessed on: July $\left.10^{\text {th }}, 2020\right)$ (in Vietnamese).

[2] Central Committee of the Communist Party of Vietnam, Resolution No. 29-NQ-TW of the 8th Lenum of Central Committee of the Communist Party of Vietnam on the Substantive and Comprehensive Renewal of Education and Training, https://vietnamlawmagazine.vn/partysets-nine-solutions-for-comprehensive-renewalof-education-3416.html/, 2020 (accessed on: June $\left.15^{\text {th }}, 2020\right)$ (in Vietnamese).

[3] Government of Vietnam, Prime Minister's Decision 69/QĐ-TTg dated 22 January 2019, Approving the Scheme on Improvement of Higher Education Quality During 2019-25, http://vanban.chinhphu.vn/portal/page/portal/chinhp hu/hethongvanban?class_id=2\&_page $=1 \&$ mode $=$ det ail\&document_id=196001/, 2019 (accessed on: June $\left.10^{\text {th }}, 2020\right)$ (in Vietnamese).

[4] Y. Gao, J. Liu, International Student Recruitment Campaign: Experiences of Selected Flagship University in China, Higher Education, Vol. 80, 2020, pp 663-678, https://doi.org/10.1007/s10734020-00503-8.

[5] T. Mazzarol, G. Soutar, Push-pull Factors Influencing International Student Destination Choice, International Journal of Educational Management, 16, 2002, pp. 82-90, https://doi.org/10.1108/09513540210418403.

[6] OECD, Education at a Glance: OECD Indicators, Paris: OECD Publishings, 2019,

https://www.oecd.org/education/education-at-aglance/, 2019 (accessed on: July 15 ${ }^{\text {th }}, 2020$ ).

[7] S. W. Lee, Circulating East to East: Understanding the Push-Pull Factors of Chinese Students Studying in Korea, Journal of Studies in International Education, Vol. 21, No. 2, 2017, pp. 170-190, https://doi.org/10.1177/1028315317697540.

[8] S. Ahmad, F. R. Buchanan, Choices of Destination for Transnational Higher Education: "Pull" Factors in an Asia Pacific Market, Educational Studies, Vol. 42, 2016, pp. 163-180, https://doi.org/10.1080/03055698.2016.1152171.

[9] A. M. Alemu, J. Cordier, Factors Influencing International Student Satisfaction in Korean Universities, International Journal of Educational Development, Vol. 57, 2017, pp. 54-64, https://doi.org/10.1016/j.ijedudev.2017.08.006.

[10] M. K. Shahijan, S. Rezaei, M. Amin, International Students' Course Satisfaction and Continuance Behavioral Intention in Higher Education Setting: 
An Empirical Assessment in Malaysia, Asia Pacific Educ, Rev, Vol. 17, 2016, pp. 41-62, https://doi.org/10.1007/s12564-015-9410-9.

[11] R. Ammigan, E. Jones, Improving the Student Experience: Learning From a Comparative Study of International Student Satisfaction, Journal of Studies in International Education, Vol. 22, No. 4, 2018, pp. 283-301, https://doi.org/10.1177/1028315318773137.

[12] Ministry of Education (China), Statistical Report on International Students in China for 2018, 18 April, 2019, http://en.moe.gov.cn/news/press_releases/201904/t20190 418_378586.html/, 2019 (accessed on: July 15 ${ }^{\text {th }}, 2020$ ).

[13] F. Dervin, A. Härkönen, X. Du, International Students in China: A Dream Come True?, in F. Dervin, A. Härkönen, X. Du, International Students in China: Education, Student Life, and Intercultural Encounters, Cham: Palgrave Macmillan, 2018, pp 1-14.

[14] Z. Lu, W. Li, M. Li, Y. Chen, Destination China: International Students in Chengdu, International Migration, Vol. 57, 2019, pp. 354-372, https://doi.org/10.1111/imig.12464.

[15] X. Ding, Exploring the Experiences of International Students in China, Journal of Studies in International Education, Vol. 20, No. 4, 2016, pp. 319-338, https://doi.org/10.1177/1028315316647164.

[16] M. A. Jiani, Why and How International Students Choose Mainland China as a Higher Education Study Abroad Destination, High Educ, Vol. 74, 2017, pp. 563-579, https://doi.org/10.1007/s10734016-0066-0.

[17] E. L. Park, Analysis of Korean Students' International Mobility by 2-D Model: Driving Force Factor and Directional Factor, Higher Education, Vol. 57, No. 6, 2008, pp. 741-755, https://doi.org/10.1007/s10734-008-9173-x.

[18] A. Ahmad, M. Shah, International Students' Choice to Study in China: An Exploratory Study, Tertiary Education and Management, Vol. 24, No. 4, 2018, pp. 325-337, https://doi.org/10.1080/13583883.2018.1458247.

[19] C. Gbollie, S. Gong, Emerging Destination Mobility: Exploring African and Asian International Students' Push-pull Factors and Motivations to Study in China, International Journal of Education Management, Vol. 34, No. 1, 2020, pp. 18-34, https://doi.org/10.1108/IJEM-02-2019-0041.

[20] A H. S. Ma, The Development of International Student Recruitment Policies in Taiwan: A 60-Year Trajectory, Journal of Studies in International Education, Vol. 18, No. 2, 2014, pp. 120-140, https://doi.org/10.1177/1028315312473781.

[21] Pulsenews, Students Rises to All-time High in S. Korea, 30 August 2019,

https://pulsenews.co.kr/view.php?year=2019\&no=68 0611/, 2019 (accessed on: June 30 ${ }^{\text {th }}, 2020$ ).

[22] D. DeAeth, Foreign Students in Taiwan $10 \%$ of Total University and College Students in 2018, Taiwan News, 03 Febuary 2019, https://www.taiwannews.com.tw/en/news/3631340/, 2019 (accessed on: June 30 $0^{\text {th }}, 2020$ ).

[23] A. Roberts, P. Chou, G Ching, Contemporary Trends in East Asian Higher Education: Dispositions of International Students in a Taiwan University, High Educ, Vol. 59, 2010, pp. 149-166, https://doi.org/10.1007/s10734-009-9239-4.

[24] H. H. Wang, C. W. Chang, You Don't Know What Really Matters to Me!: Examining the Gaps Between Governmental Policies and Student Perspectives in International Student Recruiment Practices in Taiwan, Journal of Research in Education Sciences, Vol. 61, No. 4, 2016, pp. 243-270, https://doi.org/10.6209/JORIES.2016.61(4).09.

[25] ICEF Monitor, Korea Aims for 200,000 Foreign Students by 2023, 13 October 2015, https://monitor.icef.com/2015/10/korea-aims-for200000-foreign-students-by-2023/，2015 (accessed on: June $\left.15^{\text {th }}, 2020\right)$.

[26] Statista, Number of Foreign Students in Korea, 2020, https://www.statista.com/statistics/876030/numberof-foreign-students-in-south-korea/, 2020 (accessed on: October $\left.10^{\text {th }}, 2020\right)$.

[27] Yonhap News Agency, Number of Foreign Students Drops in Korea for $1^{\text {st }}$ time in 6 Years, The Korea Herald, 27 August 2020,

http://www.koreaherald.com/view.php?ud=2020082 7000920/, 2020 (accessed on: October 10 ${ }^{\text {th }}, 2020$ ).

[28] J. E, Jon, J. J. Lee, K. Byun, The Emergence of a Regional Hub: Comparing International Student Choices and Experiences in South Korea, Higher Education, Vol. 67, 2014, pp. 691-710, https://doi.org/10.1007/s10734-013-9674-0.

[29] VNU-HCM, Annual Report 2019, Ho Chi Minh City: VNU-HCM Press, 2020 (in Vietnamese).

[30] Office of External Relations and Research Affairs (University of Social Sciences and Humanities, VNU-HCM), Report on External Relations 2015-2019, 2020 (in Vietnamese).

[31] L. Hoang, Global Manufacturers are Flocking to Vietnam, Is it Ready?, Nikkei Asia, 11 November 2020, https://asia.nikkei.com/Economy/Trade/Globalmanufacturers-are-flocking-to-Vietnam.-Is-it-ready/, 2020 (accessed on: December 10 ${ }^{\text {th }}, 2020$ ). 